\begin{tabular}{|l|l|l|}
\hline \multicolumn{2}{|c|}{ PublisherInfo } \\
\hline \hline PublisherName & $:$ & BioMed Central \\
\hline \hline PublisherLocation & $:$ & London \\
\hline \hline PublisherImprintName & $:$ & BioMed Central \\
\hline \hline
\end{tabular}

\title{
Biocompatible membranes in acute renal failure
}

\begin{tabular}{|l|l|l||}
\hline \multicolumn{2}{|c|}{ ArticleInfo } \\
\hline \hline ArticleID & $:$ & 4205 \\
\hline \hline ArticleDOI & $:$ & $10.1186 /$ ccf-2000-5398 \\
\hline \hline ArticleCitationID & $:$ & 5398 \\
\hline \hline ArticleSequenceNumber & $:$ & 64 \\
\hline \hline ArticleCategory & $:$ & Paper Report \\
\hline \hline ArticleFirstPage & $:$ & 1 \\
\hline \hline ArticleLastPage & $:$ & 3 \\
\hline \hline & $:$ & RegistrationDate : 2000-6-5 \\
ArticleHistory & $:$ & OnlineDate \\
\hline \hline ArticleCopyright & $:$ & Current Science Ltd2000-6-5 \\
\hline \hline ArticleGrants & $:$ & \\
\hline \hline ArticleContext & $:$ & 1305422 \\
\hline \hline
\end{tabular}


Bruce Powell, ${ }^{\text {Aff1 }}$

Aff1 Northern General Hospital, Sheffield

\section{Keywords}

Acute renal failure, apoptosis, cytokines, dialysis, membrane bicompatibility, superoxide

\section{Comments}

Does the choice of dialyser membrane affect outcome in the treatment of acute renal failure (ARF)? Work by many research groups has failed to conclusively prove the benefit of biocompatible membranes on the activation of selected cellular responses. This well designed but under-powered crossover study candidly admits to showing no measureable outcome benefit in the use of biocompatible membranes and concludes that evidence to back the use of such membranes is still under investigation. The large number of exclusions, on clinical grounds, raises doubts about the validity of any conclusions drawn from the study. Also, the use of intermittant haemodialysis (IHD) as the mode of treatment, limits the relevance of the paper to the intensive therapy unit setting. However, the choice of dialyser membrane is of potential concern in all modes of renal replacemnet therapy, both continuous venovenous haemofiltration $(\mathrm{CVVH})$ and IHD, and any demonstrable impact on survival would be very valuable in what is a high mortality group.

\section{Introduction}

ARF requiring haemodialysis carries a mortality rate approaching $60 \%$. Whether the choice of dialyser membrane has an impact on outcome is unproven. Even in those trials showing a positive result, the biological basis behind the apparent improvement was not examined. There is a good body of evidence, from trials in chronic renal failure, that dialysis with non-biocompatible membranes leads to cytokine release and the production of free radicals. This trial attempts to clarify whether the choice of membrane impacts on pro- and anti-inflammatory cytokine levels, superoxide release from neutrophils, and cellular apoptosis in ARF.

\section{Methods}


Single centre 20 month study of 24 patients admitted with acute renal failure requiring IHD. Exclusion criteria included pregnancy, positive HIV status, previous transplants, documented chronic renal insufficiency or isolated ultrafiltration for fluid overload. The patients were assigned alternately to either cellulose acetate or polysulfone membrane intermittent haemodialysis and baseline demographic and clinical data recorded. Blood samples were collected prior to the first of three IHD sessions and then repeated before crossing the patient over to the other membrane. At each time point, cytokine production, superoxide release and cellular apoptosis were determined and compared with the type of dialysis membrane, nutritional indices and the adequacy of dialysis.

\section{Results}

Of 181 consecutive admissions with ARF initiated on IHD, 152 were excluded because of preexisting conditions or emergency IHD prior to enrolment. There were no significant differences in any of the measured parameters and thus no benefit was demonstrated from the use of a biocompatible membrane.

\section{References}

1. Jaber BL, Cendoroglo M, Balakrishnan VS, Perianayagam MC, Karsou SA, Ruthazer R, King AJ, Pereira BJ: Impact of dialyser membrane selection on cellular responses in acute renal failure. Kidney Int. 2000, 57: 2107-2116. 